\title{
SIMULATION OF ROUNDNESS, HARDNESS AND MICROSTRUCTURE OF BEARING RINGS WITH THIN CROSS SECTIONS BY USING SYSWELD
}

The roller bearing is a component which helps to reduce friction on relative rotational or sliding movements of the machine parts. Nowadays, there are many kinds of rolling bearings whose production is constantly improving due to increasing demands on the mechanical properties and durability. An important and necessary step in the production of rolling bearings is the heat treatment. Technological heating process must be created rationally for the required mechanical properties such as hardness, toughness and also dimensional accuracy all with respect to the economic efficiency. Because of the economical demands, simulation software is increasingly beginning to be used in the projection of heat treatment. This simulation software can predict metallurgical and mechanical properties of components after heat treatment, and thus it is easier to select the optimal material design, heat treatment process and it can possibly identify construction deficiencies in the selected part. For simulation of the heat treatment the SWYSWELD software from ESI group was used. As the output value after the simulated heat treatment (quenching) was hardness, composition of microstructure, roundness and residual stresses. These results of the simulation were then compared with the real measured values [1, 2 and 3].

Keywords: Bearing ring, SYSWELD, hardness, roundness, 100CrMnSi6-4, quenching.

\section{Material characteristic and diameters of the bearing rings}

As an experimental model the outer bearing ring (Fig. 1) was chosen. This ring is made of modified bearing steel named $100 \mathrm{CrMnSi6}-4$ whose chemical composition is in accordance with ISO 683-17 shown in Table 1. Thanks to alloying elements, this modified steel has increased hardenability compared to the basic steel $100 \mathrm{Cr} 6$ which is used for producing thin wall bearing rings and glands.

The $100 \mathrm{CrMnSi} 6-4$ steel is used for production of bearing rings of a diameter exceeding $30 \mathrm{~mm}$, bearing balls, tapered rollers, barrels with diameters up to $35 \mathrm{~mm}$ and rings with wall thickness up to $45 \mathrm{~mm}$. Interval of austenitizing temperature for hardening is from 830 to $870{ }^{\circ} \mathrm{C}$. The quenching process takes place in a mineral oil to achieve the desired hardness values. Usual tempering temperatures are from 150 to $180^{\circ} \mathrm{C}$. Manufactured rings prescribed hardness after quenching min. 64 HRC hardness and after tempering 59+4 HRC. Maximum allowable roundness after quenching is $0.2 \mathrm{~mm}$ recommended by the manufacturer [4 and 5].

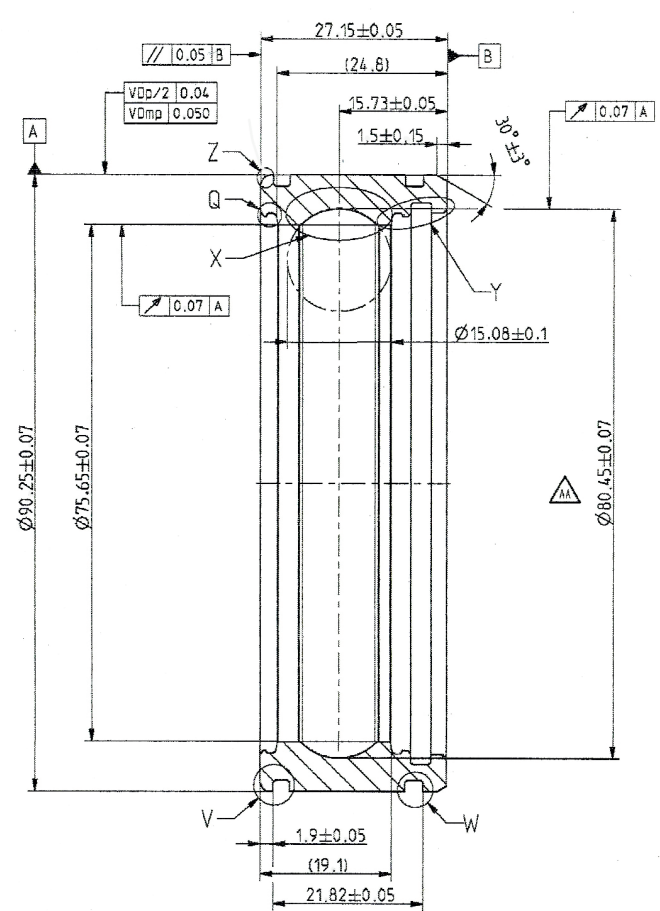

Fig. 1 Parameters of the experimental bearing ring

\footnotetext{
* Peter Fabian, Peter Jankejech, Martina Kyselova

Department of Technological Engineering, Faculty of Mechanical Engineering, University of Zilina, Slovakia

E-mail: peter.fabian@fstroj.uniza.sk
} 


\begin{tabular}{|c|c|c|c|c|c|c|c|}
\hline $\mathrm{C}$ & $\mathrm{Cr}$ & $\mathrm{Mn}$ & $\mathrm{Si}$ & $\mathrm{P}$ & $\mathrm{S}$ & $\mathrm{Ni}$ & Mo \\
\hline $0.9-1.05$ & $1.4-1.65$ & $1-1.02$ & $0.5-0.7$ & Max. 0.03 & Max. 0.025 & Max. 0.3 & $0-0.1$ \\
\hline
\end{tabular}

\section{Short description of the simulation software SYSWELD}

The SYSWELD software is designed to simulate and evaluate different methods of welding and heat treatment which works on the finite element method (FEM). The program can simulate volumetric and surface heat treatment and thermo-mechanical heat treatment (carburizing, nitriding and nitro-carburizing). The calculation of SYSWELD software is divided into two stages. The first stage contains thermo-metallurgical calculation and the second stage mechanical calculation. Thermo-metallurgical part analyses the calculation of non-stationary temperature fields, phase transformation, hardness structure or austenitic grain size. Mechanical analysis follows the thermo-metallurgical analysis and allows the calculation of waveforms of stress tensor components, the value of principal stresses, analysis of the spatial stress conditions according to the HMH theory and also Tresc analysis of shear stresses. Simulation (calculation) is based on measured data which form the internal database. These data are specific for each material, and depend on the chemical composition of the material [1, 6 and 7].

\section{Heat treatment parameters of the outer ring}

During the heat treatment of the outer ring the standardized parameters recommended by the manufacturer were used. These parameters were taken from the CCT diagram and tempering diagram for $100 \mathrm{CrMnSi6}-4$ bearing steel.

Heating of the outer ring took place in the intermediate chamber furnace with protective atmosphere. Austenitizing temperature was carried out at $850^{\circ} \mathrm{C}$ for 20 minutes, but when moving the ring by belt elevator the temperature dropped to $10^{\circ} \mathrm{C}$. As a quenching medium the quenching oil Marquench 875 was used. After completing the quenching process, the ring was put into the tempering furnace at a temperature of $190^{\circ} \mathrm{C}$ for about 120 minutes. These are the basic parameters that are needed for the SYSWELD software to make the simulation of the heat treatment. More detailed information is not necessary for the numerical simulation because the software can' $t$ take this information into account [1 and 7].

\section{Creating the 3D model for simulation}

For the simulation of heat treatment of the outer ring the input parameters of a real technological process were used. First, it was necessary to create a model that had a defined volume. The volume consists of grids that are important for simulation. It is, therefore, necessary to define the density of these grids. The higher the density is, the more accurate the calculation is, but also time-consuming. When the volume of the outer ring was finished the surface of the model had to be defined. The surface of the model also consists of grids for heat transfer simulation (Fig. 2). It is necessary to know what features or what part of the model (the ring) is the most important for the results. In this case it is the surface layer. Therefore, the density gratings in the surface layer must be greater than the whole volume of the outer ring (Fig. 3). The coating has a thickness of $0.1 \mathrm{~mm}$ and consists of five other layers. Other layers have a thickness of $0.5 \mathrm{~mm}$. For the computer simulation of mechanical processes there is a need to define trhee points of the model. The first point is anchored in all three axes. The second point is anchored in two axes and the last in only one axis. Diagram of the model is shown in Fig. 4.
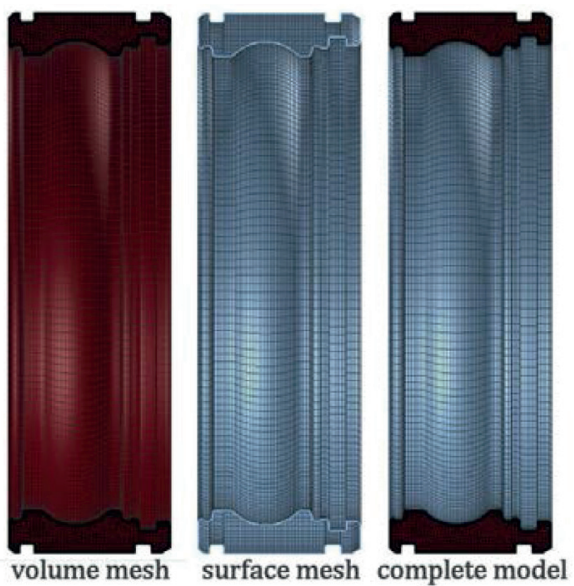

Fig. 2 3D model of the outer bearing ring 


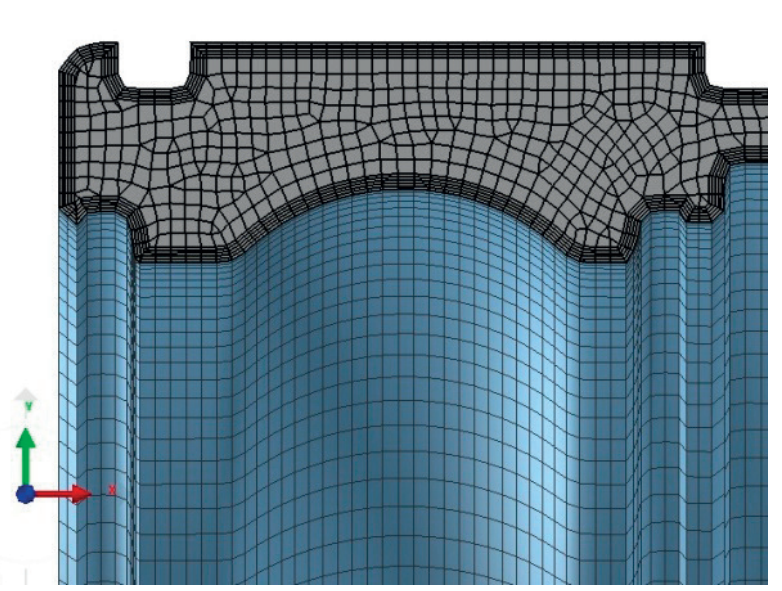

Fig. 3 Cross section of the outer ring and the representation of the surface layer

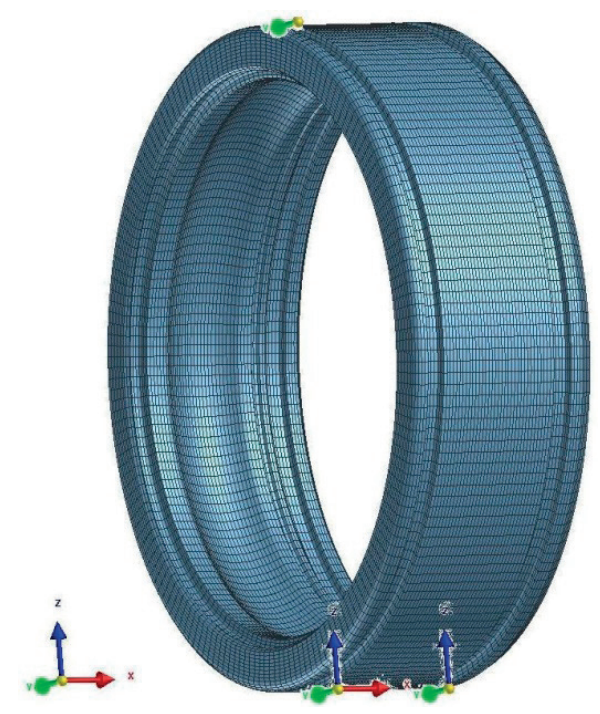

Fig. 4 Scheme of the outer ring in the SYSWELD software

After creating the model and selecting the material properties from the internal database, all input data were entered into the application HT (heat treatment) consultant which is part of the SYSWELD software. We focused on two parts of the computer simulation. First part consists of thermo-metallurgical analysis, the second part of mechanical. These two parts were selected because of the comparison of microstructure and hardness with the real measured values [8 and 9].

\section{Results of the computer simulation}

The most important results emerging from the heat treating simulation in SYSWELD is hardness, microstructure, deformation and residual stresses after quenching. From Fig. 5 it is obvious that hardness has the same values in the whole volume of the outer ring. The average value of the simulated hardness was not higher than 58.8 HRC. Another output data from the simulation was the microstructure [10 and 11].

Figure 6 shows the microstructure which contains martensite and Fig. 7 residual austenite. Percentage representation of martensite and residual austenite is approximately $77 \%-23 \%$. The large presence of residual austenite is due to the fact that the outer ring was simulated after quenching. In the real process of thermal heat treatment the outer ring would undo tempering and the share of residual austenite would tumble down. The output of stresses and deformations in numerical simulation is roundness of bearing rings which is a consequence of uneven distribution of stresses (Fig. 8) during the quenching of rings. Roundness in most cases can be removed by grinding, but when the roundness is very high, it is unable to remove it. Numerical simulation in this case shows relatively high roundness which can be a consequence of slots that are turned around the rings (Fig. 9). The value of roundness by numerical simulation is $93 \mu \mathrm{m}$. All the results of numerical simulation represent non-tempered state because tempering can ' $t$ be simulated by this software [12 and 13].

\section{HARDNESS NOD (-1) $\min =784.444$ at $N$ NOE 40779
$\max =784.446$ at $N O D E$
8329}
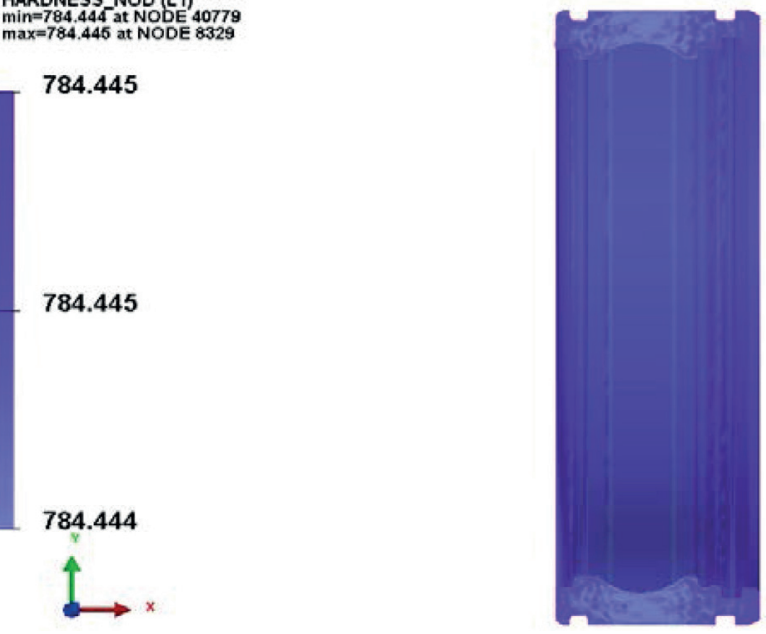

Fig. 5 The result of heat treating simulation focused on hardness

\section{Real measured values of the outer ring}

Hardness of the experimental ring was measured by the Rockwell and Vickers method on certified devices. The measurement procedure of Vickers method consists of placing stitches perpendicular to the axis of the ring. This measurement was repeated three times at random locations on the surface of the outer ring. The average value of hardness on the surface of the outer ring was $734 \mathrm{HV} 1 / 10$. Rockwell hardness was measured on the front side of the ring. Its average value was not higher than 60 HRC. Microstructure of the ring was etched with 
PHASE PROPORTIONS NOD_3(L1) $\min =0 . \overline{77} 0070$ at NODE $2 \overline{3} 347$
$\max =0.770074$ at NODE 20675

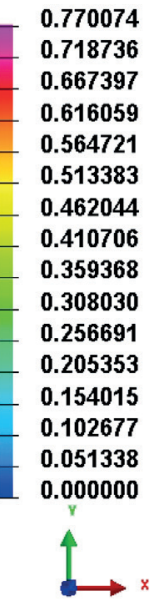

Fig. 6 Percentage representation of martensite in the microstructure

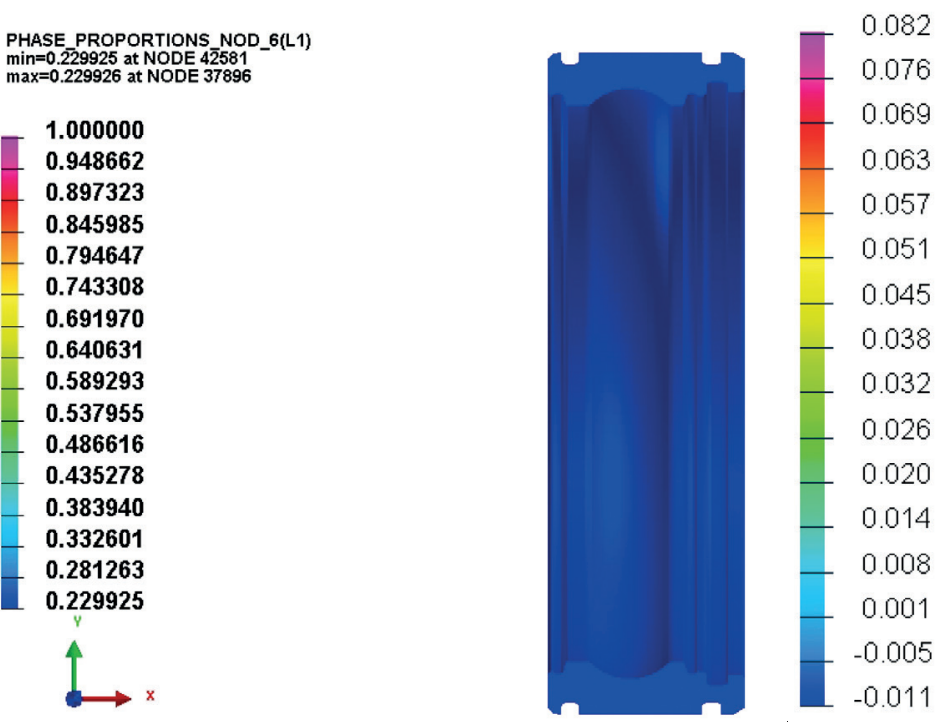

Fig. 7 Percentage representation of residual austenite in the microstructure

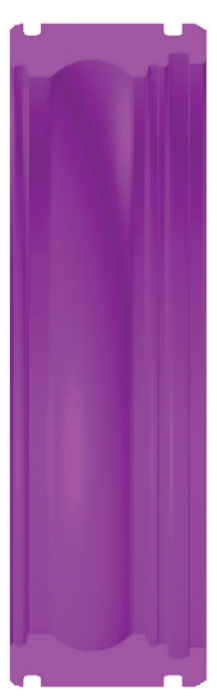

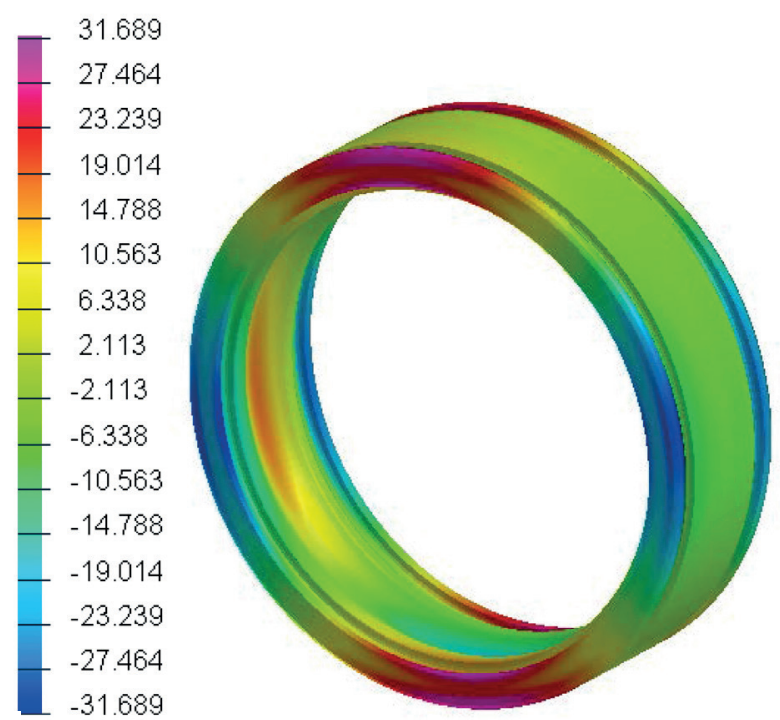

Fig. 8 Result of residual stress simulation

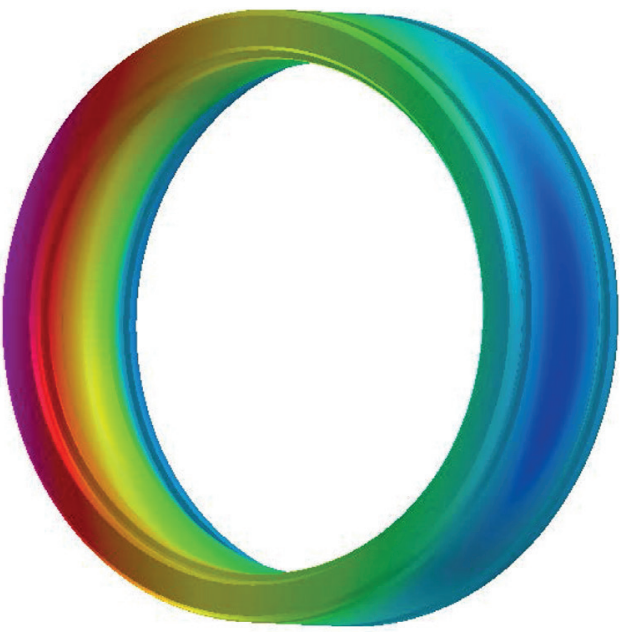

Fig. 9 Result of roundness simulation picric acid and observed on a light microscope. Figure 11 shows the microstructure in which martensite forms the greater part and retained austenite the lower part. Carbides are uniformly distributed (white dots). Roundness of the outer ring was measured using a 3D measuring apparatus, in two perpendicular diameters in the same ring plane. Roundness values are shown in Fig. 10 .

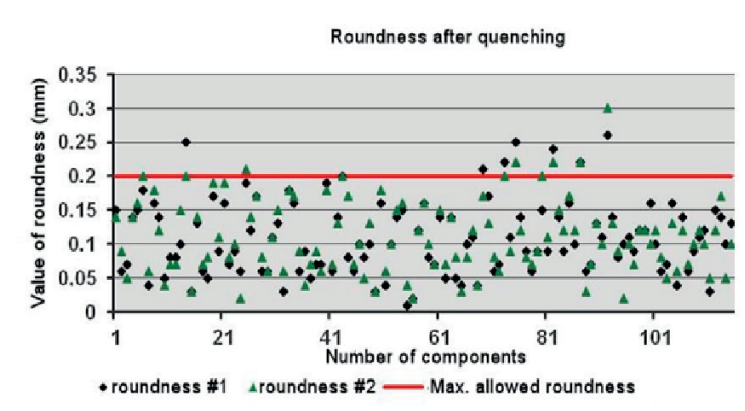

Fig. 10 Values of roundness 


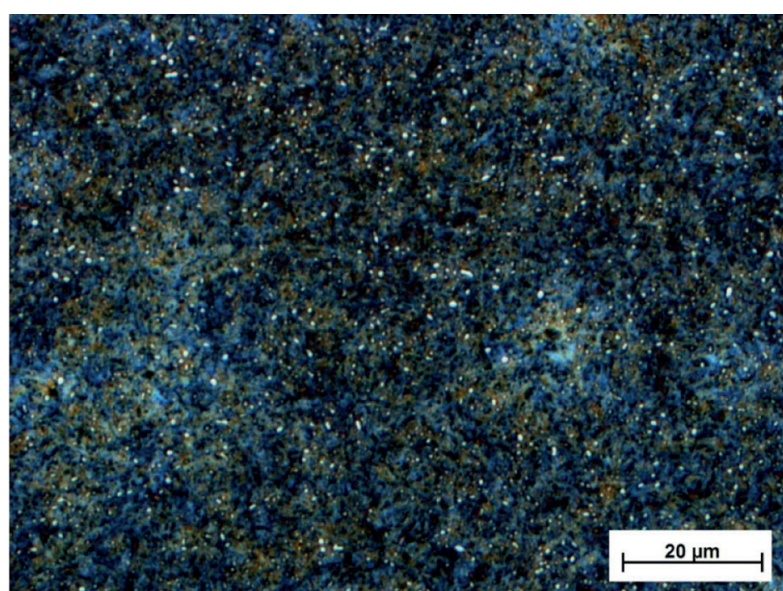

Fig. 11 The microstructure of the 100CrMnSi6-4 bearing steel, Magnification 1250x.

\section{Conclusion}

The aim of this experiment was to compare the results from simulation of heat treatment of the outer ring which was made of material $100 \mathrm{CrMnSi} 6$ - 4 with the actual measured values. Roundness of the ring came to $93 \mu \mathrm{m}$. The values of actually measured roundness were from 30 to $40 \mu \mathrm{m}$. That means these values from real measurement were from 0.05 to 0.06 millimeters smaller than simulated. When comparing the microstructure and hardness of the true values, these simulated results are close to reality. It should be noted that the ring is not the final product of heat treatment because it has to be tempered to reduce distortion and residual austenite after hardening, together with a reduction of hardness. The measured values indicate that the calculation program SYSWELD can be used to simulate the heat treatment for the purpose of predicting the values such as hardness, microstructure and roundness in the process of cooling. The roundness may contain extreme values in some rings $[14,15$ and 16].

\section{Acknowledgement}

The work has been supported by the grant project APVV SK-PL_0034-12: Research of Tribological Properties of Electrospark Deposited Coatings.

\section{References}

[1] KONAR, R., MICIAN, M.: Numerical Simulation of Residual Stresses and Distortions in butt Weld in Simulation Programme Sysweld. Communications - Scientific Letters of the University of Zilina, vol.14, No. 3, 2012, 49-54, ISSN 1335-4205

[2] BREZNICAN, M., FABIAN, P., MESKO, J., DRBUL, M.: The Simulation of Influence of Quenching Temperature on Properties of Bearing Rings, Manufacturing Technology: J. for Science, Research and Production, vol. 13, No. 1, 2013, 20-25, ISSN 1213-2489

[3] FABIAN, P., KECKOVA, E., BETAK, P.: Metals Heat Treatment, Zilina 2007, 113 p., ISBN 978-80-969592-7-3

[4] KONAR, R., MICIAN, M., HOPKO, A.: Analysis of Boundary Conditions for the Simulation of Welding at the Repair of Gas Pipelines with Steel Sleeve, Communications - Scientific Letters of the University of Zilina, vol. 13, No. 4, 2011, 36-39, ISSN 13354205

[5] TOTTEN, G.: Steel Heat Treatment: Metallurgy and Technologies, Boca Raton: Taylor \& Francis Group LLC, 2006,820 p., ISBN 978-0-8493-8455-4.

[6] KANG, S. H., IM, Y. T.: Thermo-elasto-plastic Finite Elements Analysis of Quenching Process of Carbon Steel. J. of Materials Processing Technology, No. 192-193, 2007, 381 -390.

[7] HAKAN GUR, C.. PAN, J.: Handbook of Thermal Process Modeling of Steels, 2008, 342-380, Taylor \& Francis Group LLC, Boca Raton.

[8] PASTIRCAK, R., KRIVOS, E.: Effect of Opening Material Granularity on the Mould Properties and the Quaility of Castings Made by Patternless Process Technology, Manufacturing Technology: J. for Science, Research and Production, vol. 13, No. 1, 2013, 92-97, ISSN 1213-2489.

[9] PASTIRCAK, R., URGELA, D., KRIVOS, E.: Production of Castings by Patternless Process, Archives of Foundry Engineering, vol. 12, No. 1, 2012, 87-92, ISSN 1897-3310

[10] BRONCEK, J., DZIMKO, M., HADZIMA, B., TAKEICHI, J.: Acta Metallurgica Slovaca, vol. 20, No. 1, 2014, 97-104, DOI 10.12776/ams.v20i1.273

[11] PETRU, M., NOVAK, O., HERAK, D.: Biosystems Engineering, vol. 111, No. 4, 2012, 412 -421, DOI:10.1016/j. biosystemseng.2012.01.008 
[12] RADEK, N., SLADEK, A., BRONCEK, J., BILSKA, I., SZCZOTOK, A.: Electrospark Alloying of Carbon Steel with WC-CoAl2O3: Deposition Technique and Coating Properties, Advanced Materials Research, vol. 874, 101-106, (C) (2014) Trans Tech Publications, Switzerland, doi:10.4028/www.scientific.net/AMR.874, ISSN 1022-6680

[13] JANKURA, D., DRAGANOVSKA, D., BREZINOVA, J.: Chemické listy, vol. 105, No. 16, 2011, 542-545

[14] PIETRAZSEK, J., GADEK-MOSCZAK, N., RADEK, N.: Studies in Computational Intelligence, vol. 513, No. 1, 2014, 125-134, DOI:10.1007/978-3-319-01787-7_12

[15] TOMAS, M., DRAGANOVSKA, D., HUDAK, J., IZOL, P.: Acta Metallurgica Slovaca, vol. 20, No. 1, 2014, 105-114, DOI 10.12776/ams.v20i1.274

[16] CZICHOS, H., HABIG, K. H.: Tribologie - Hanbuch, Reibung und Verschleiss, VERLAG VIEWEG, 1992, 456 p. 